\title{
The prevalence of thrombocytopenia in pregnant women in Baghdad: single centre study
}

\author{
Eaman M. Muhammad* \\ Ekhlass H. Sabri* \\ Hussam D. Saeed $* *$
}

\author{
FICOG, CABOG \\ FICOG, CABOG \\ FIBMS
}

\section{Abstract:}

JFac Med Baghdad 2018; Vol.60, No .2 Received Mar. 2018 Accepted May. 2018

Background: The prevalence of thrombocytopenia in most studies ranges from 7 to $10 \%$ of all pregnant females. Although pregnancy is associated with physiological changes that may affect platelet count, several pathological conditions can cause thrombocytopenia which have a significant impact on both the mother and her baby.

Objective: The aim of this study was to determine the prevalence of thrombocytopenia in pregnant women attending an out-patient clinic in Al-Yarmouk Teaching hospital in Baghdad.

Material and Methods: A cross sectional study conducted at Al-Yarmouk Teaching Hospital from 1st October 2016 to 1 st July 2017. Five hundred sixty pregnant women randomly selected as the study group and another 100 non-pregnant women as the control group were enrolled in this study. A complete blood count and blood film were done for both the selected groups.

Results: Thrombocytopenia was found in $7.1 \%$ of the cases. The most common cause of thrombocytopenia was gestational thrombocytopenia seen in 19(47.5\%) patients and PE \& HELLP syndrome $9(22.5 \%)$ patients. Most of our cases were asymptomatic and only one case developed heavy vaginal bleeding while there were 2 cases who had platelets below 50,000 considered as severe thrombocytopenia without significant bleeding.

Conclusion: Thrombocytopenia is not a rare condition in pregnancy. Accurate etiological diagnosis is essential for effective management. Most of the cases are mild, self-limiting and rarely cause with complications

Keywords: prevalence, Thrombocytopenia, Pregnancy,

\section{Introduction:}

Thrombocytopenia is defined as a platelet count of less than $150 \times 109 / \mathrm{L}$ as generally is defined in normal individuals and the incidence is around 7 $10 \%$ in pregnant women (1). The platelet count in pregnancy is slightly lower than non-pregnant women (2). Most studies report a reduction in platelet count during pregnancy around 10\% less than non-pregnant women. Thrombocytopenia in pregnancy is relatively a common condition. Although the pregnancy itself is associated with a hypercoagulable states, there are several wellestablished causes of thrombocytopenia such as pregnancy induced hypertension, preeclampsia, HELLP syndrome, and immune thrombocytopenic purpura $(3,4,5,6)$. However, the majority of thrombocytopenic women are healthy, have no history of thrombocytopenia nor have hypertensive disorders and the platelets level return to normal within three months post-delivery and this reduction in platelet level usually has no effect neither on the mothers nor on their newborns(5). Thrombocytopenia is classified into mild where platelet count range from $100-150 \times 109 / \mathrm{L}$, moderate form $50-100 \times 109 / \mathrm{L}$, and severe with a count less than $50 \times 109 /$ L. Gestational thrombocytopenia is

\footnotetext{
* Dept. of Ob/Gyn, Al- Yarmouk Teaching Hospital Email: dreaman_alani@yahoo.com **Department Com. Med. / College of Medicinel University of Al-Iraqia.
}

the most prevalent cause, and accounts for about $75 \%$ of cases of thrombocytopenia during pregnancy (7). Its aetiology is still unclear, although it might be secondary to increased platelet consumption, plasma volume expansion associated and chronic compensated coagulopathy(8). 15-20\% of the cases are secondary to hypertensive disorders which include pregnancy induced hypertension (PIH), Preeclampsia (PE) and HELLP syndrome; 3-4\% due to immune thrombocytopenic purpura (ITP), and around $1-2 \%$ due to infections. Malignancies and constitutional thrombocytopenia $(9,10)$. Rarely it is caused by thrombotic thrombocytopenic purpura (TTP), haemolytic uremic syndrome (HUS), disseminated intravascular coagulation (DIC), systemic lupus erythematosus (SLE), antiphospholipid syndrome or drug induced (such as heparin) (7). The current study was carried out in a single centre in Baghdad trying to estimate the prevalence of thrombocytopaenia in Iraqi pregnant women.

\section{Materials and Methods}

This is a cross sectional, observational study carried out from $1^{\text {st }}$ October 2016 to $1^{\text {st }}$ of July 2017. A total of 560 pregnant women enrolled in this study. They were at different gestational age attended outpatient clinic or admitted to the obstetric ward and delivery room at Al-Yarmouk Teaching Hospital/ obstetrics and gynaecology department. All were screened for thrombocytopenia. There were no exclusion criteria 
all normal and complicated pregnant women were included into this study. Another 100 healthy nonpregnant women during thier reproductive life was taken as the control group during the period of this study. The later were mostly out-patient relatives of other patients who agreed to do a complete blood test. A detailed history was taken and a thorough examination was done after obtaining their consent. The study was approved by ethical committee of AlYarmouk teaching Hospital

About $2.5 \mathrm{ml}$ blood was taken from each pregnant women and control in an EDTA tube to perform full blood count using auto-analyzer machine (Celltac /Japan) which was calibrated every month by the manufactures controls. In pre-eclamptic women an extra $5 \mathrm{ml}$ of blood was taken in a plain tube for the measurement of renal and liver functions. Coagulation tests including Prothrombin time (PT), Partial thromboplastine Time (PTT) and plasma fibrinogen level were assessed for any pregnant women presenting with bleeding manifestation or thrombocytopenia detected on the screening test using the fully automated coagulation STA COMPACT (BIO kits of Biolabo/ France ) .

Statistical analysis: Statistical analysis was performed using the Microsoft $₫$ Excel, Professional Edition 2010. Descriptive statistics (means and percentage) are mostly presented. Statistical significance was calculated using the Chi-square. A p-value of $<0.05$ was considered statistically significant.

\section{Results:}

A total of 560 pregnant women were included in this study, their ages ranged between 17-40 years (mean 28.3 years). The control group included 100 apparently healthy non-pregnant women with ages ranged between 20 and 47 years (mean of 31.6 years). The mean platelets count of the pregnant women was 217.38 and thrombocytopenia was found in $7.1 \%$ of them as shown in figure 1and table 1.

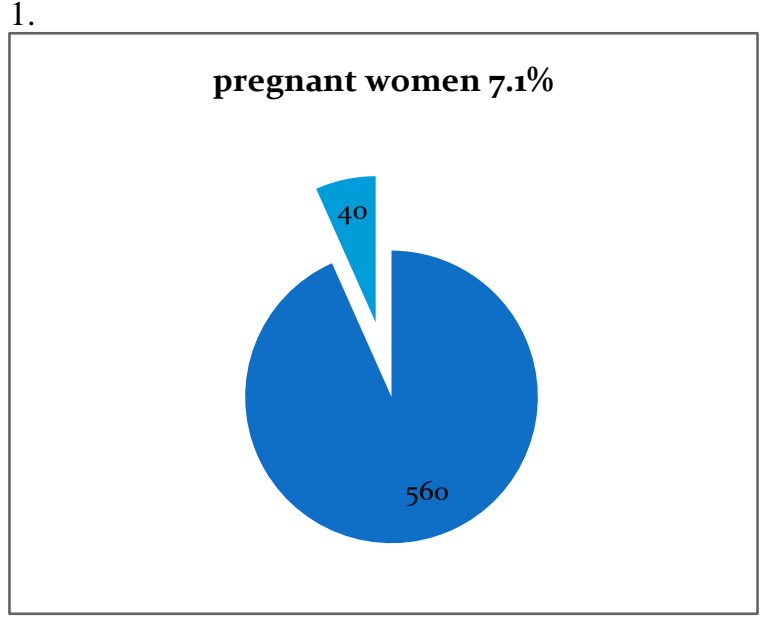

Figure 1: No. of thrombocytopenia in pregnant women.
Table 1: No. of symptomatic pregnant women

\begin{tabular}{rr}
\hline No symptoms & $39 / 40(97.5 \%)$ \\
\hline Cutaneous bleeding & 0 \\
\hline Vaginal bleeding & $1 / 40(2.5 \%)$ \\
\hline
\end{tabular}

Table 2: the relationship between gestational age and thrombocytopenia

\begin{tabular}{lll}
$\begin{array}{l}\text { Clinical } \\
\text { characteristics }\end{array}$ & $\begin{array}{l}\text { Thrombocytopenic } \\
\text { women }\end{array}$ & $\begin{array}{l}\text { Non } \\
\text { thrombocytopenic }\end{array}$ \\
\hline $\begin{array}{l}\text { Throughout } \\
\text { pregnancy }\end{array}$ & $40 / 560(7.1 \%)$ & $520 / 560(92.9 \%)$ \\
\hline trimester 1 $\underline{\text { st }}$ & $0(0 \%)$ & $123(100 \%)$ \\
\hline trimester 2 $\underline{\text { nd }}$ & $11 / 560(7.9 \%)$ & $127(92.1 \%)$ \\
\hline 3 rd trimester & $29 / 560(9.7 \%)$ & $270(90.3 \%)$ \\
\hline
\end{tabular}

The chi-square statistic is $\mathbf{1 0 . 3 8 5 3}$. The $p$-value is $\mathbf{. 0 1 5 5 6}$. The result is significant at $p<.05$

Table 3: the relationship between parity and thrombocytopenia

\begin{tabular}{lrr} 
Parity & \multicolumn{1}{l}{ Thrombocytopenic } & Non-thrombocytopenic \\
\hline P0 & $5(3.4 \%)$ & $146(96.6 \%)$ \\
P1-4 & $35(9.8 \%)$ & $334(90.2 \%)$ \\
P5+ & $0(0 \%)$ & $40(100 \%)$
\end{tabular}

The chi-square statistic is 7.57. The p-value is $\mathbf{. 0 2 2 6 2 7 . ~ T h e ~}$ result is significant at $p<.05$

The majority of the pregnant women that were diagnosed with thrombocytopenia were beyond the 2nd half of their pregnancy as shown in table 2.

Five out of the forty $(12.5 \%)$ of thrombocytopenic cases were nulliparas while the other were multiparas but not grand multiparas as shown in table 3

Table 4: The aetiologies of Thrombocytopenia in the Study Group

\begin{tabular}{ll}
\hline Causes & $\mathrm{N}=40$ \\
\hline Gestational thrombocytopenia & $19(47.5 \%)$ \\
PET and HELLP syndrome & $9(22.5 \%)$ \\
Missed Abortion & $4(10 \%)$ \\
\hline IUD & $4(10 \%)$ \\
\hline Placental Abruption & $2(5 \%)$ \\
\hline Hepatic Diseases & $1(2.5 \%)$ \\
\hline ITP & $1(2.5 \%)$ \\
\hline
\end{tabular}




\begin{tabular}{|c|c|c|c|c|}
\hline Causes & $\begin{array}{l}\text { Mild } \\
\text { thrombocy } \\
\text { topenia }\end{array}$ & $\begin{array}{l}\text { Moderate } \\
\text { thrombocy } \\
\text { topenia }\end{array}$ & $\begin{array}{l}\text { Severe } \\
\text { thrombocy } \\
\text { topenia }\end{array}$ & $\begin{array}{l}\mathrm{N}= \\
40\end{array}$ \\
\hline $\begin{array}{l}\text { Gestationa } \\
1 \\
\text { thrombocy } \\
\text { topenia }\end{array}$ & 17 & 2 & 0 & 19 \\
\hline $\begin{array}{l}\text { PET and } \\
\text { HELLP } \\
\text { syndrome }\end{array}$ & 7 & 1 & 1 & 9 \\
\hline $\begin{array}{l}\text { Missed } \\
\text { Abortion }\end{array}$ & 3 & 1 & 0 & 4 \\
\hline IUD & 2 & 2 & 0 & 4 \\
\hline $\begin{array}{l}\text { Placental } \\
\text { abruption }\end{array}$ & 2 & 0 & 0 & 2 \\
\hline $\begin{array}{l}\text { Hepatic } \\
\text { Diseases }\end{array}$ & 1 & 0 & 0 & 1 \\
\hline ITP & 0 & 0 & 1 & 1 \\
\hline
\end{tabular}

\section{Discussion:}

This single centre study was conducted to estimate the prevalence of thrombocytopenia in pregnancy in Baghdad at Alyarmouk teaching hospital and to evaluate the most identifiable causes behind it. The reduction in platelet count during pregnancy is generally less symptomatic due to the hypercoagulable state induced by increased levels of von Willebrand Factor (VWF), fibrinogen and factor VIII, with reduction in both protein $\mathrm{S}$ activity and fibrinolysis(11). Thrombocytopenia has become a cause for additional testing and even interventions(12). The incidence in current study was $7.1 \%$ which is comparable to other studies done in Erbil(13), Sulaymania(14) in Iraq and even to other studies all over the word like USA(15)and UK(16). Tejashwini et al(17) in his study showed that platelet count was significantly decreased during pregnancy as compared to puerperium in the same woman due to increased platelet consumption by placenta and haemodilution. Usha et al (18) stated that although thrombocytopenia during pregnancy was common, it was not frequently severe). This was consistent with our study results as the majority of thrombocytopenic cases $(80 \%)$ were within the mild thrombocytopenic group (100 -150 $\times 109 / \mathrm{L})$. Unlike other studies where gestational thrombocytopenia is the main cause of thrombocytopenia in pregnancy $(, 19,20)$, gestational thrombocytopenia was found in less than half of our patients which is similar to a study done in India by Hina et al(21).Pre-eclampsia and HELLP syndrome is the second most common aetiology that was found in our study which is similar to a study done by Pallavi et al(19) Severe thrombocytopenia where platelet count is less than $50 \times 109 / \mathrm{L}$ was found in two cases one of them HELLP syndrome and was given platelet transfusion and stabilized and delivered safely. The other case was ITP in the

second trimester of missed miscarriage and also correction of platelet count by steroid and platelet transfusion and termination of pregnancy was done and then referred to the haematological team. Interestingly none of the cases complicated by severe vaginal bleeding and blood transfusion was needed in only the HELLP case due to DIC but she improved after delivery and discharged well from hospital.

\section{Conclusion:}

Although around half of cases are gestational thrombocytopenia, it still the commonest cause of thrombocytopenia in pregnancy Preeclampsia \& HELLP are the second most causes of it. The majority of the cases are mild and self-limiting and are not associated with significant bleeding. The incidence of thrombocytopenia increases with gestational age being more common in third trimester than in second and first trimester It is more commonly seen in multigravida rather than primigravida

\section{Authors' contributions:}

Eaman Marouf and Ekhlass Hussam Sabri , both obstetrics and gynaecology seniors, collected the cases, took the samples from the pregnant women and the control, classified the causes and followed the patients.

Hussam Dawod Saeed an assistant prof., community department, performed the statistical analysis of the study

\section{References:}

1. Shehata N, Burrows R, Kelton JG. Gestational thrombocytopenia. Clin Obstet Gynecol 1999;42:327-34.

2. Abbassi-Ghanavati, M., Greer, L.G. \& Cunningham, F.G. Pregnancy and laboratory administrative data, a reference table for clinicians. Obstetrics \& Gynecology 2006, 114, 1326-1331.

3. Verdy, E., Bessous, V., Dreyfus, M., Kaplan, C., Tchernia, G. \& Uzan, S. Longitudinal analysis of platelet count and volume in normal pregnancy. Thrombosis and Haemostasis1997, 77, 806 -807.

4. Levy JA, Murphy LD. Thrombocytopenia in pregnancy.J Am Board FamPract 2002; 15:290-7.

5. Myers B. Thrombocytopenia in pregnancy. Obstet Gynecol 2009; 11(3):177-183.

6. Huparikar Anita et al. Thrombocytopenia in pregnancy. Indian Journal of Obstetrics and Gynaecology Research 2016;3(1):7-12

7. Kam PC, Thompson SA, Liew AC. Review article: thrombocytopenia in the parturient. Anaesthesia 2004;59:255-64

8. Fay, R.A., Hughes, A.O. \& Farron, N.T. Platelets in pregnancy: hyperdestruction in pregnancy. Obstetrics \& Gynecology 1983; 61, 238

9. Bethan Myers.Review article: Diagnosis and management of maternal thrombocytopenia in pregnancy. British Journal of Haematology, 2012, $158,3-15$ 
10. Lain KY,Roberts JM. Contemporary concepts of the pathogenesis and management of preeclampsia. J Am Med Assoc 2002; 287:3183-6.

11. Calderwood, C. Thromboembolism and thrombophilia in pregnancy. Current Obstetrics \& Gynaecology 2006; 16, 321-326.

12. Sainio S, Kekomäki R, Riikonen S, Teramo K. Maternal thrombocytopenia at term: a populationbased study. Acta Obstet Gynecol Scand 2000;79:744-9.

13. Shamoon et al. Causes of thrombocytopenia during pregnancy.Turk J Hematol 2009; 26: 123-8.

14. Asmaa M Thanoon. Thrombocytopenia in Iraqi Pregnant Women. J Fac Med Baghdad 2011; 53:171-174.

15. Anita Rajasekhar, MD, MS Terry Gernsheimer, MD Roberto Stasi, MD, PhD Andra H. James, MD, MPH Clinical Practice Guide on Thrombocytopenia in Pregnancy. American Society of Hematology2013.
16. Bethan Myers. Diagnosis and management of maternal thrombocytopenia in pregnancy. British Journal of Haematology, 2012; 158, 3-15.

17. Tejashwini VB, Spoorthi BS, Saryu Sain. A comparative study of change in platelet count in pregnancy and puerperium. IJCAP 2015; 2(2): 108110.

18. Perepu U, Rosenstein L. Maternal thrombocytopenia in pregnancy. Proc Obstet Gynecol 2013; 3(1): 6.

19. Pallavi Satish V ishwekar, R. K. Yadav, Coneel B. Gohel. Thrombocytopenia during Pregnancy and Its Outcome. JKIMSU2017; 6, 82-89.

20. Anna Jodkowska, Helena Martynowicz, Beata Kaczmarek-Wdowiak, Grzegorz Mazur.Thrombocytopenia in pregnancy pathogenesis and diagnostic approach. Postepy Hig Med Dosw (online), 2015; tom 69: 1215-1221.

21. Hina Ozal, Mitesh Priydarshi, Nidhi Pancholi3. Prevalence and Characterization of Thrombocytopenia in Pregnancy in Indian Women. Int J Res Med. 2017; 5(4); 60-63 